\title{
Effectiveness of dietary interventions on weight outcomes in childhood: a systematic review meta-analysis of randomized controlled trials
}

\author{
Qi Long', Ting Zhang ${ }^{1}$, Fei Chen ${ }^{1}$, Wenqiao Wang ${ }^{1}$, Xia Chen ${ }^{1}$, Ming Ma ${ }^{1,2}$ \\ ${ }^{1}$ Department of Clinical Nutrition, Children's Hospital of Zhejiang University School of Medicine, National Clinical Research Center for Child \\ Health, Hangzhou, China; ${ }^{2}$ Department of Pediatrics, The Fourth Affiliated Hospital of Zhejiang University School of Medicine, Hangzhou, China \\ Contributions: (I) Conception and design: Q Long, M Ma; (II) Administrative support: F Chen, W Wang; (III) Provision of study materials or patients: \\ None; (IV) Collection and assembly of data: Q Long, X Chen; (V) Data analysis and interpretation: T Zhang; (VI) Manuscript writing: All authors; \\ (VII) Final approval of manuscript: All authors. \\ Correspondence to: Ming Ma. Department of clinical Nutrition, Children's Hospital of Zhejiang University School of Medicine, National clinical \\ research center for child health, Hangzhou, China; Department of Pediatrics, The fourth Affiliated Hospital of Zhejiang University School of \\ Medicine, Hangzhou, China. Email: maming73@zju.edu.cn.
}

\begin{abstract}
Background: Rapid growth and elevated weight in childhood are significantly associated with obesity in later life, but evidence regarding dietary interventions and weight outcomes is lacking. This study aimed to determine the effectiveness of dietary interventions on body mass index (BMI) and BMI z-score in childhood. Methods: PubMed, EmBase, and the Cochrane library were searched from inception till June 2019. Studies that investigated the effectiveness of dietary interventions on BMI and BMI z-score in childhood were considered eligible in our study. The changes in BMI and BMI z-score between dietary interventions and control were calculated by pooled weighted mean differences (WMDs) and 95\% CIs were evaluated using random-effects model.
\end{abstract}

Results: Twenty-eight randomized controlled trials involving a total of 17,488 children were included. The summary WMDs indicated that children who received dietary interventions had greater reduction in BMI (WMD: -0.12 ; 95\% CI: -0.20 to $-0.05 ; \mathrm{P}=0.001$ ) and BMI z-score (WMD: $-0.04 ; 95 \% \mathrm{CI}:-0.06$ to -0.02 ; $\mathrm{P}=0.001$ ) when compared to the usual controls. Subgroup analyses revealed that the sample size, mean age, duration of interventions, and study quality could affect the effectiveness of dietary interventions in children. Conclusions: The findings of this meta-analysis suggested that dietary interventions improved BMI and BMI z-score, whereas these results are limited due to substantial heterogeneity and study quality of the included studies.

Keywords: Dietary interventions; weight outcomes; childhood; meta-analysis; randomized controlled trials

Submitted Jul 11, 2020. Accepted for publication Feb 06, 2021.

doi: $10.21037 /$ tp-20-183

View this article at: http://dx.doi.org/10.21037/tp-20-183

\section{Introduction}

Childhood obesity is mainly associated with wide range of adverse psychosocial and physical health outcomes. Therefore, an effective intervention strategy should be developed for preventing childhood obesity, as it is significantly correlated with public health (1). According to a previous study, the effectiveness of early intervention in the first few years of life for preventing overweight and obesity is clearly evident, and the prevalence of overweight is nearly $6.7 \%$ in children below 5 years of age (2). Although overweight during infancy is significantly correlated with the occurrence of obesity during childhood, adolescents, and adulthood, the occurrence of overweight during infancy might not be diagnosed by the providers $(3,4)$. Previous 
studies have reported that educated mothers focused on both nutritional as well as environmental aspects, which played an important role in preventing non-communicable diseases (5). However, it is still controversial whether dietary interventions through education affects the weight outcomes in childhood.

Nowadays, numerous factors are associated with the progression of obesity in childhood, which included infant feeding practices, children's eating habits and television watching time, and these are the most modifiable factors (6-10). Moreover, infant feeding practices showed significant correlation with the eating behaviors of children as well as adults in the later life (11). Therefore, obesity-related behaviors were affected by a range of settings, especially the dietary interventions. Recently, several interventional strategies have been employed for preventing and treating childhood obesity, whereas these intervention strategies provided controversial results with slight reduction in the body mass index (BMI) $(12,13)$. Numerous randomized controlled trials (RCTs), some participants were preschool age children (14-17) and others were school-age children (18-41), have already investigated the role of dietary interventions on BMI and BMI z-score in childhood, whereas the effect estimates varied owing to differences in the intervention theories. Therefore, we attempted to comprehensively examine the published RCTs for determining the effectiveness of dietary interventions on weight outcomes in childhood. Moreover, stratified analyses were conducted to explore whether the effectiveness of interventions differed according to the sample size, mean age, duration of interventions, and study quality.

We present the following article in accordance with the Preferred Reporting Items for Systematic Reviews and Meta-Analysis (PRISMA) Statement reporting checklist (42) (available at http://dx.doi.org/10.21037/tp-20-183).

\section{Methods}

\section{Etbical statement}

Institutional Review Board approval was not required because this article is a meta-analysis. The data comes from published articles and does not require ethical approval.

\section{Data sources, search strategy, and selection criteria}

Studies that are designed as RCTs and those that evaluated the effectiveness of dietary interventions on BMI or BMI z-score were considered eligible for inclusion in this metaanalysis, and there was no restriction to published language and status. PubMed, EmBase, and the Cochrane library were systematically searched for studies published from inception till June 2019. The core search terms used were as follows: ("child*" OR "infant") AND ("health education" OR "school health services" OR "child health services" OR "community health planning" OR "primary health care" OR "child nutrition sciences" OR "child nutrition disorders" OR "food habits" OR "nutrition assessment" OR "diet" OR "diet therapy"). Moreover, the reference lists of the obtained studies were manually searched for inclusion of any new study.

Two independent authors conducted the literature search and study selection processes, and any disagreement was resolved by discussion with each other until a consensus was reached. Studies were included if they met the following inclusion criteria: (I) study design: studies with RCT design; (II) participants: all individuals were less than 18.0 years, irrespective of their weight status; (III) intervention: individuals who received medical health education containing dietary contents; (IV) control: usual health program; and (V) outcomes: studies reporting BMI or BMI z-score.

\section{Data collection and quality assessment}

The collected information from the retrieved studies included the first authors' surname, publication year, country, sample size, mean age, intervention populations, dietary intervention target, control, duration of intervention, and changes in BMI or BMI z-score. The quality assessment was evaluated using the Cochrane Collaboration risk of bias instrument, and each item was answered with yes, no, or unclear (43). Data collection and quality assessment were conducted by 2 authors, and any conflicts were resolved by an additional author by referring to the original article.

\section{Statistical analysis}

The effectiveness of dietary interventions on BMI or BMI z-score in childhood was used as continuous variable based on the mean, standard deviation, and sample size in each individual trial. The summary weighted mean differences (WMDs) with its 95\% CIs were used to calculate the effect size of dietary interventions by using randomeffects model $(44,45) . \mathrm{I}^{2}$ and $\mathrm{Q}$ statistics were employed to 


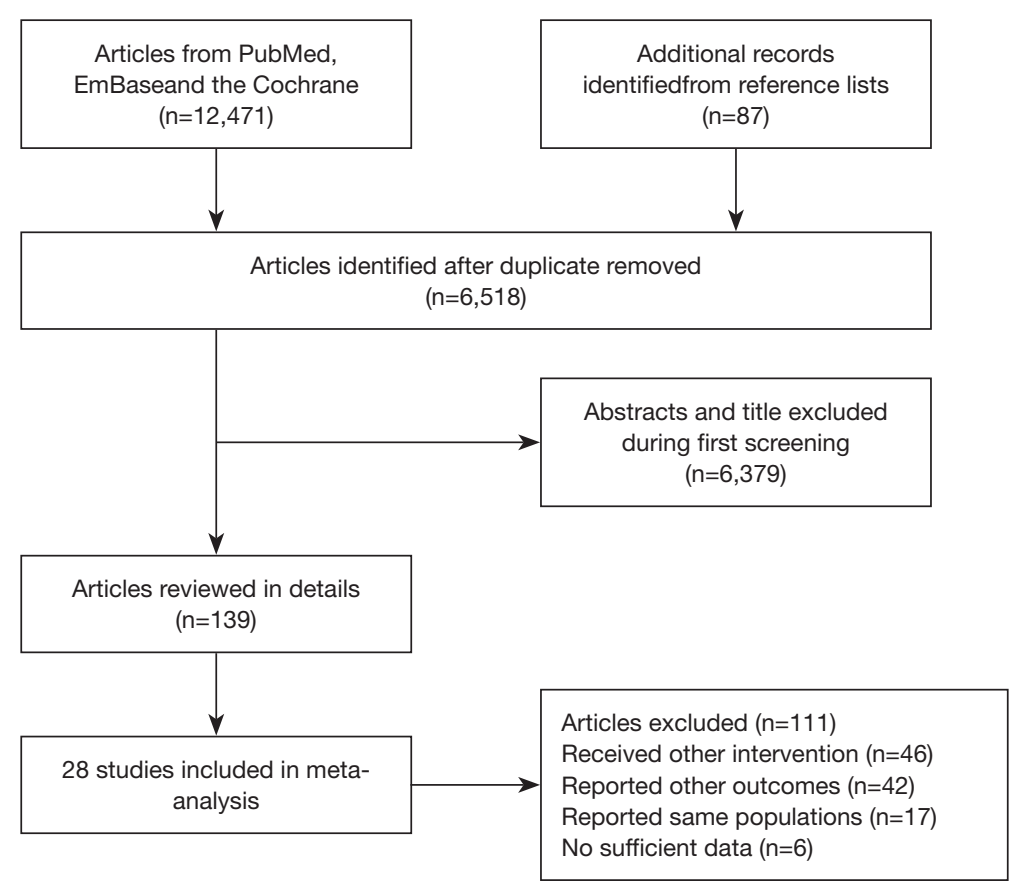

Figure 1 Flowchart of study selection process.

assess the heterogeneity across the included trials, and $\mathrm{I}^{2}$ $>50.0 \%$ or $\mathrm{P}<0.10$ was regarded as significant heterogeneity $(46,47)$. Sensitivity analyses for BMI and BMI z-score were carried out to assess the impact of each trial from the overall analysis (48). Subgroup analyses for BMI and BMI z-score were conducted based on sample size, mean age, duration of interventions, and study quality to evaluate the effectiveness of dietary interventions according to the study or individuals' characteristics. After this, the $\mathrm{P}$ value between subgroups was compared through interaction test using Student's $t$-test as the number of included studies was small (49). Publication biases for BMI and BMI z-score were evaluated using funnel plot, Egger (50), and Begg (51) tests, and $\mathrm{P}<0.10$ was considered as potentially significant publication bias. The inspection level for pooled results was 2 -sided, and $\mathrm{P}<0.05$ was regarded as statistically significant. All analyses in this study were conducted using STATA software (Version 10.0; Stata Corporation, College Station, TX, USA).

\section{Results}

\section{Literature search}

Our initial electronic database search yielded 12,471 records. Of these, 5,953 articles were excluded due to duplications. After that, the title and abstract of the remaining 6,518 studies were reviewed, and 6,379 of these were excluded due to irrelevant topics. A total of 139 articles were selected for further evaluation, and 111 of these were excluded due to the following reasons: the intervention strategy did not contain the dietary content $(n=46)$; other health outcomes were reported $(n=42)$; studies reported on similar population $(n=17)$; and data on BMI or BMI z-score were not available $(\mathrm{n}=6)$. The reference lists yielded 87 potential studies, whereas all these studies were obtained from electronic searches, and so are excluded as duplicates. Finally, 28 RCTs were selected for quantitative meta-analysis. The detailed literature search and study selection process are presented in Figure 1.

\section{Study characteristics}

Of the 28 eligible RCTs, 17,488 children were included for final analysis. The baseline characteristics of the included studies and children are summarized in Table 1 . The duration of dietary interventions in individuals was 2.0-72.0 months, and each study included 106-2,950 children. The age of the children included ranged from $0.75-13.0$ years, and most of the included trials were conducted in western countries. Study quality of individual trials was shown in Table 2. 


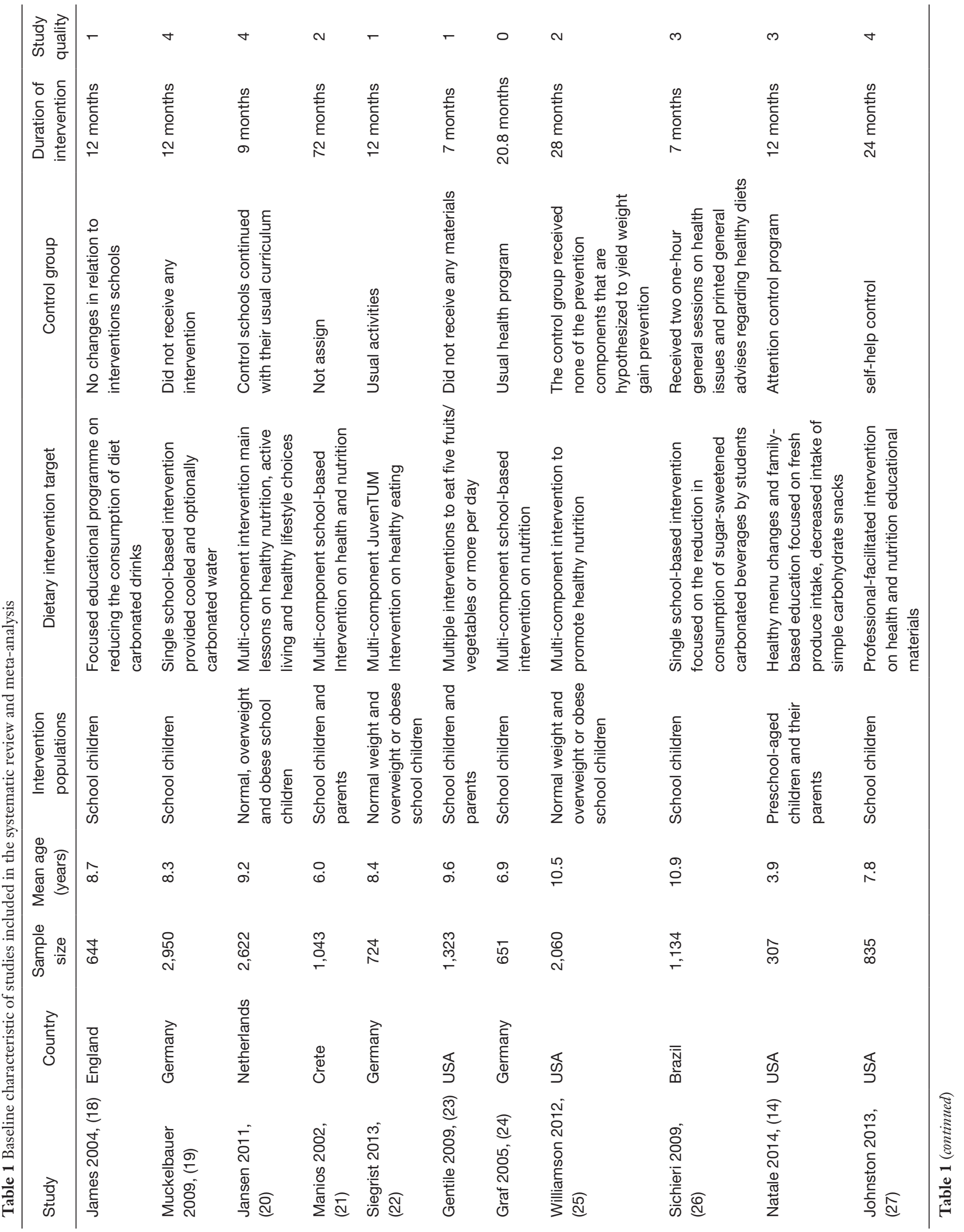




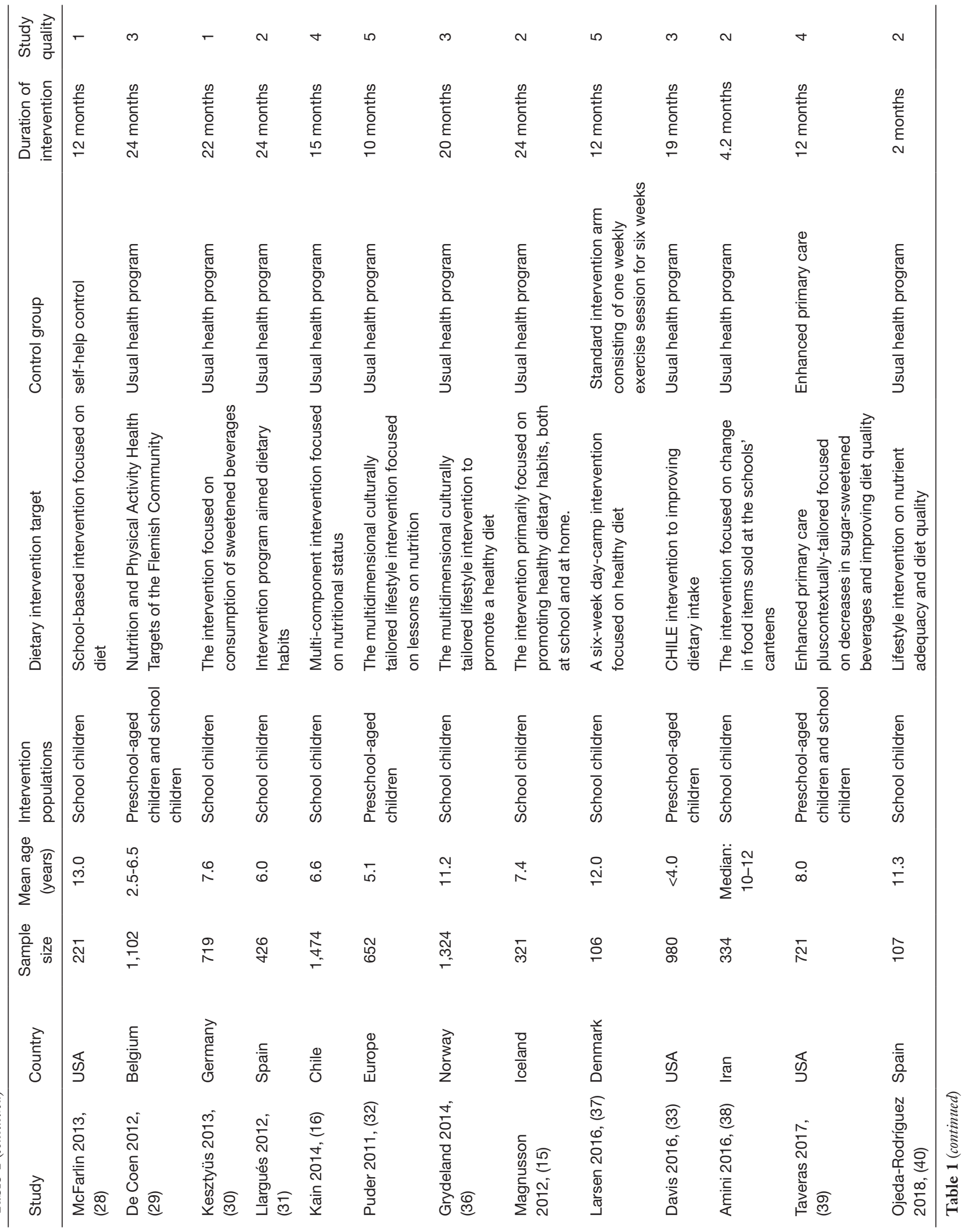




\begin{tabular}{|c|c|c|c|c|}
\hline 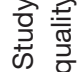 & $m$ & $m$ & م & $r$ \\
\hline 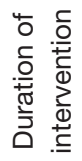 & 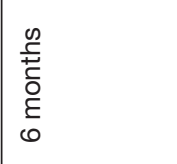 & 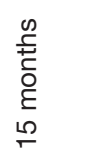 & 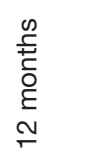 & 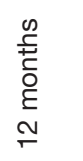 \\
\hline 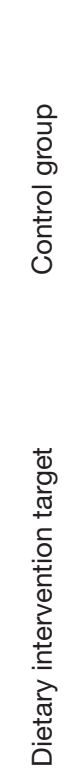 & 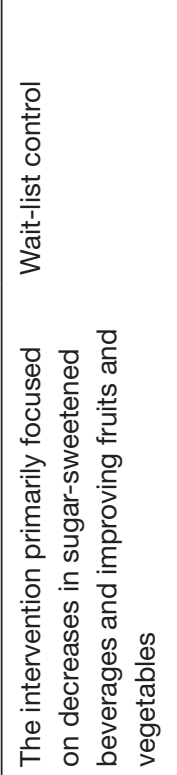 & 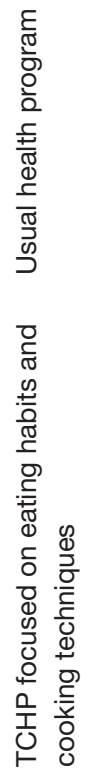 & 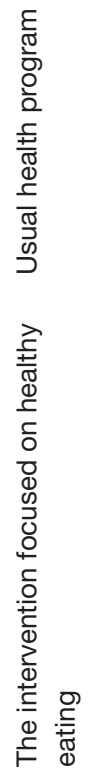 & 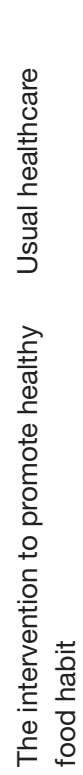 \\
\hline 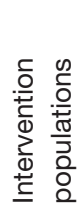 & 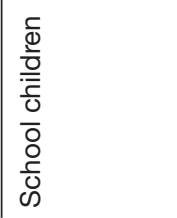 & 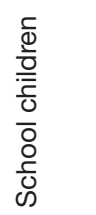 & 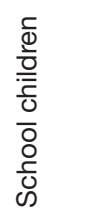 & 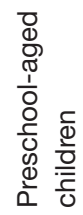 \\
\hline 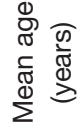 & $\stackrel{\leftrightarrow}{\circ}$ & $\check{\circ}$ & $\stackrel{m}{0}$ & $\begin{array}{l}\circ \\
\stackrel{+}{+} \\
\stackrel{5}{\rho} \\
\stackrel{2}{\circ}\end{array}$ \\
\hline $\begin{array}{l}\frac{0}{0} \\
\frac{\tilde{c}}{\tilde{E}} \\
\stackrel{N}{\infty}\end{array}$ & ঙે & 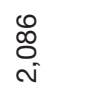 & 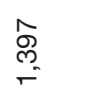 & ס. \\
\hline $\begin{array}{l}\text { 辛 } \\
\text { 亏0 } \\
\text { O }\end{array}$ & $\begin{array}{l}\frac{\frac{\pi}{0}}{\frac{\pi}{\pi}} \\
\frac{\sigma}{\tilde{\pi}}\end{array}$ & $\begin{array}{l}\frac{\bar{\Xi}}{\overline{0}} \\
\text { की }\end{array}$ & 号 & 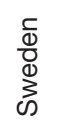 \\
\hline 辛 & 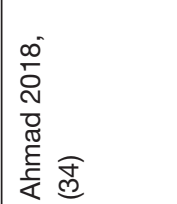 & 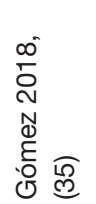 & 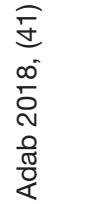 & 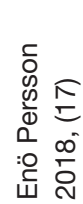 \\
\hline
\end{tabular}

\section{BMI}

Data regarding the effectiveness of dietary intervention on BMI in childhood were available in 20 trials (22 cohorts). The results revealed that children who received dietary interventions had greater reduction in BMI when compared with usual healthcare (WMD: -0.12 ; $95 \%$ CI: -0.20 to -0.05 ; $\mathrm{P}=0.001$; Figure 2), and showed a significant heterogeneity among the included trials $\left(\mathrm{I}^{2}=99.9 \% ; \mathrm{P}<0.001\right)$. The results of sensitivity analysis indicated that the conclusion was stable and unaltered by excluding any particular trial (Figure 3). Subgroup analyses indicated that dietary intervention significantly reduced BMI when compared with healthcare when the sample size $<1,000$ (WMD: -0.18 ; $95 \%$ CI: -0.37 to $-0.00 ; \mathrm{P}=0.047$ ), mean age of individuals $\leq 6.0$ (WMD: $-0.25 ; 95 \%$ CI: -0.43 to $-0.09 ; \mathrm{P}=0.002)$ or $>10.0$ years (WMD: $-0.21 ; 95 \%$ CI: -0.30 to $-0.11 ; \mathrm{P}<0.001)$, the duration of intervention $\geq 12.0$ months (WMD: -0.18 ; $95 \%$ CI: -0.27 to $-0.09 ; \mathrm{P}<0.001)$, and studies with high quality (WMD: -0.25 ; 95\% CI: -0.37 to -0.13 ; $\mathrm{P}<0.001)$. Moreover, significant effectiveness of dietary interventions on BMI could be affected by sample size, mean age, duration of intervention, and study quality (Table 3).

\section{BMI z-score}

Data regarding the effectiveness of dietary interventions on BMI z-score in childhood were available in 17 trials (18 cohorts). The summary WMD indicated that children who received dietary interventions had greater reduction in BMI z-score (WMD: $-0.04 ; 95 \%$ CI: -0.06 to $-0.02 ; \mathrm{P}=0.001$; Figure 4), showing a significant heterogeneity across the included trials $\left(\mathrm{I}^{2}=99.8 \% ; \mathrm{P}<0.001\right)$. This conclusion was unaffected by sequential exclusion of included trials (Figure 3). Subgroup analyses indicated that dietary intervention was associated with greater reduction in BMI z-score irrespective of sample size $(\geq 1,000$ : WMD, $-0.05,95 \% \mathrm{CI},-0.10$ to $-0.01, \mathrm{P}=0.020 ;<1,000$ : WMD, $-0.03,95 \% \mathrm{CI},-0.05$ to $-0.00, \mathrm{P}=0.022$ ), mean age $>10.0$ years (WMD: $-0.05 ; 95 \%$ CI: -0.06 to $-0.03 ; \mathrm{P}<0.001)$, the duration of intervention $\geq 12.0$ months (WMD: -0.04 ; $95 \%$ CI: -0.06 to -0.02 ; $\mathrm{P}<0.001$ ), and study with high quality (WMD: $-0.10 ; 95 \%$ CI: -0.17 to $-0.04 ; \mathrm{P}=0.003)$. These results suggested that the effectiveness of dietary interventions on BMI z-score was affected by sample size, mean age, and study quality (Table 3).

\section{Publication bias}

Review of funnel plots for BMI and BMI z-score did not 


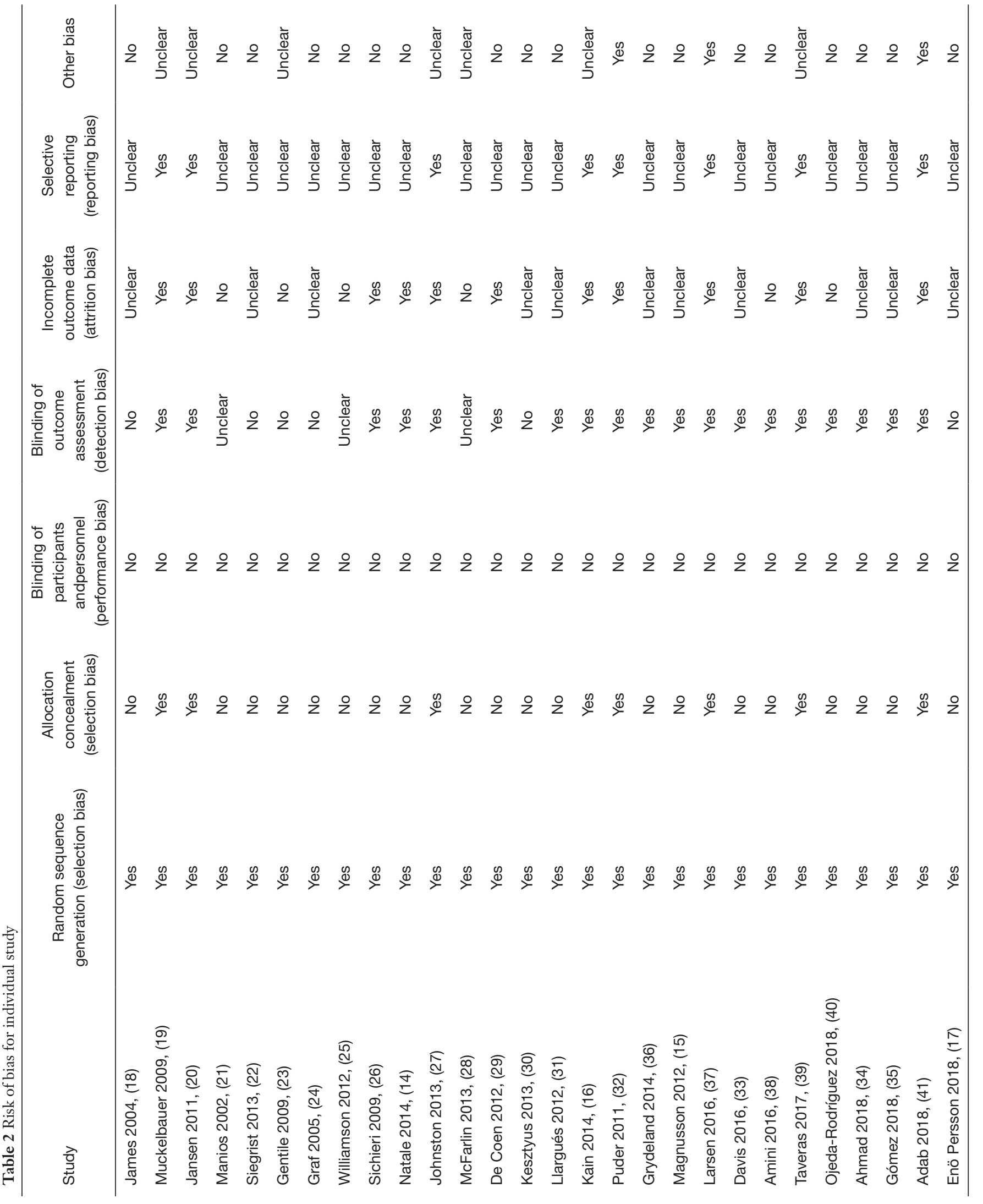




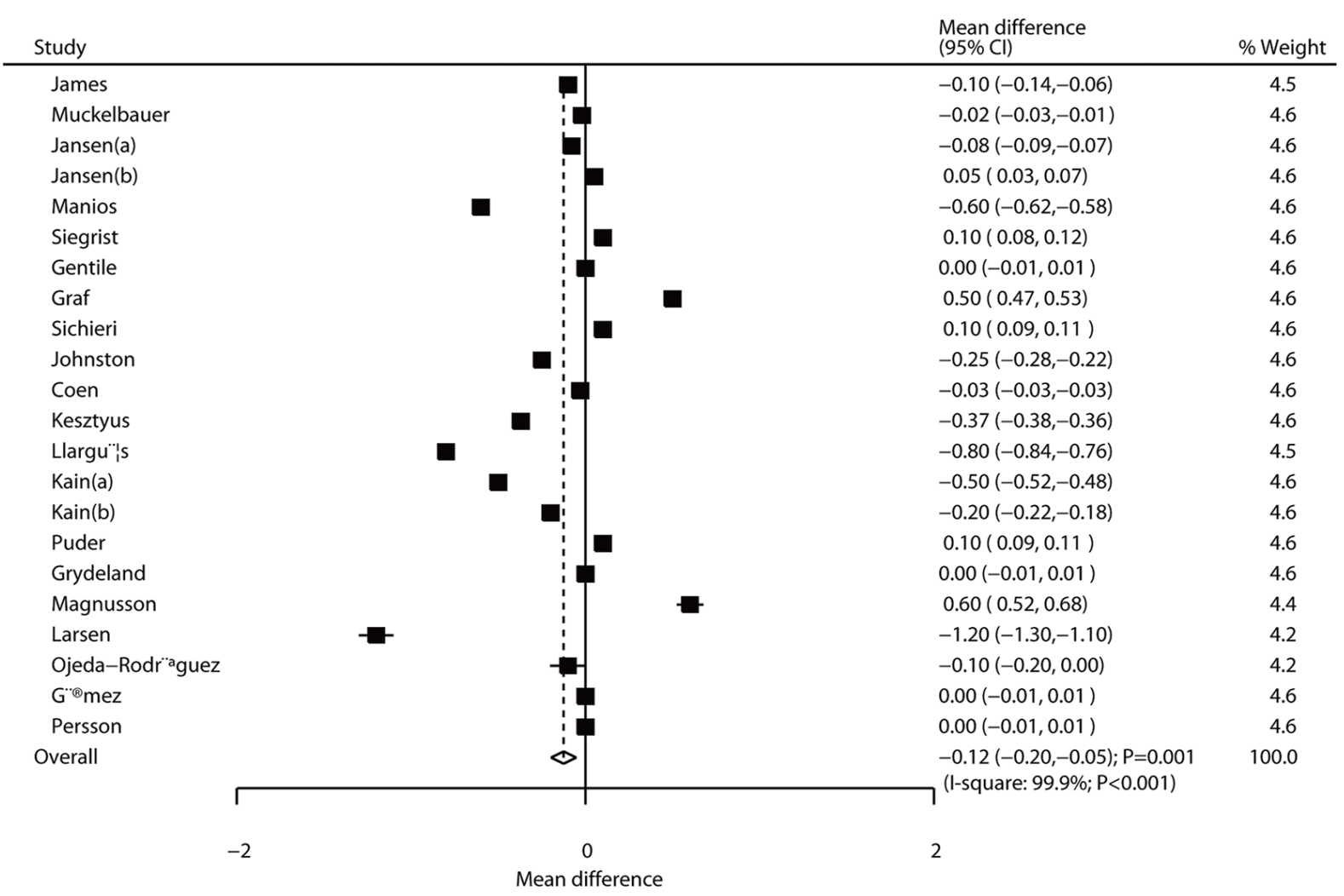

Figure 2 Effect of dietary intervention on body mass index.

yield any potential publication bias (Figure 5). The results of Egger and Begg tests showed no significant publication bias for BMI (P value for Egger: 0.477; $\mathrm{P}$ value for Begg: $0.176)$ and $\mathrm{BMI} z$-score (P value for Egger: 0.774; $\mathrm{P}$ value for Begg: 0.880).

\section{Discussion}

To our knowledge, this is the first meta-analysis study that focused on dietary intervention on weight outcomes in childhood. This quantitative meta-analysis recruited 17,488 children from 28 RCTs with varied individual characteristics. The findings of this study provided stable evidence and suggested that dietary intervention was associated with greater reduction in BMI and BMI z-score in childhood. The significant effectiveness of dietary intervention on BMI mainly focused on sample size $<1,000$, mean age of individuals $\leq 6.0$ or $>10.0$ years, duration of intervention $\geq 12.0$ months, and high quality studies, whereas significant effectiveness on BMI z-score was mainly detected irrespective of sample size, mean age $>10.0$ years, duration of intervention $\geq 12.0$ months, and high quality studies.

Several systematic reviews and meta-analyses that focused on diet, physical activity and behavioral interventions in children as well as adolescents with obesity have already been conducted. van Hoek et al. have pooled 27 studies and revealed that obese young children who received both dietary and physical activity education and behavioral therapy had the largest pooled change in BMI z-score (52). However, these results were obtained by conducting subgroup analysis of 2 studies. Brown et al. have conducted a meta-analysis of 29 studies including both South Asian children and adults. They pointed out that individuals who received diet or physical activity interventions showed significant improvement in weight, whereas no significant differences were observed in BMI and waist circumference (53). A meta-analysis conducted by Oosterhoff et al. have included 85 RCTs and found that school-based lifestyle interventions resulted in beneficial changes in BMI and blood pressure (54). A metaanalysis of 70 RCTs conducted by Mead et al. have evaluated the effectiveness of diet, physical activity and behavioral interventions in treating overweight or obese children aged 6-11 years. The results revealed that the above interventions 

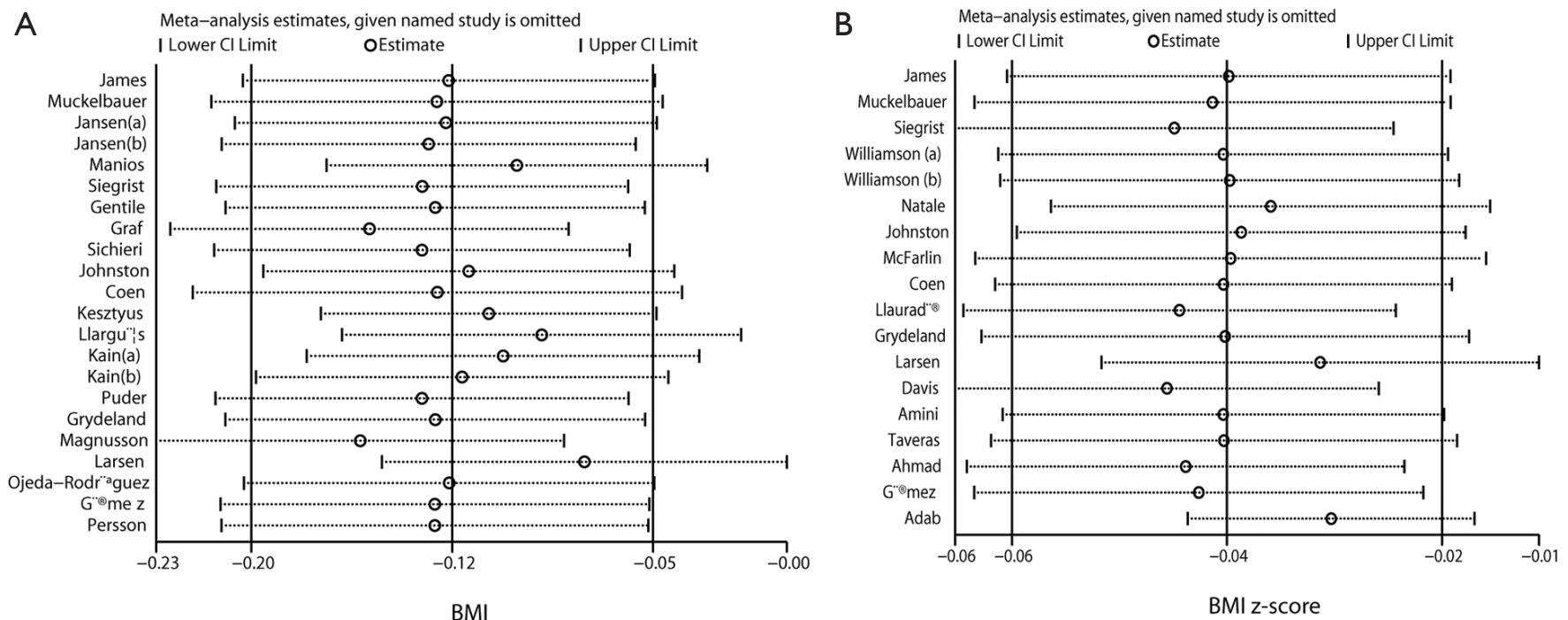

Figure 3 Sensitivity analyses for body mass index (A) and body mass index z-score (B).

Table 3 Subgroup analyses for BMI and BMI z-score

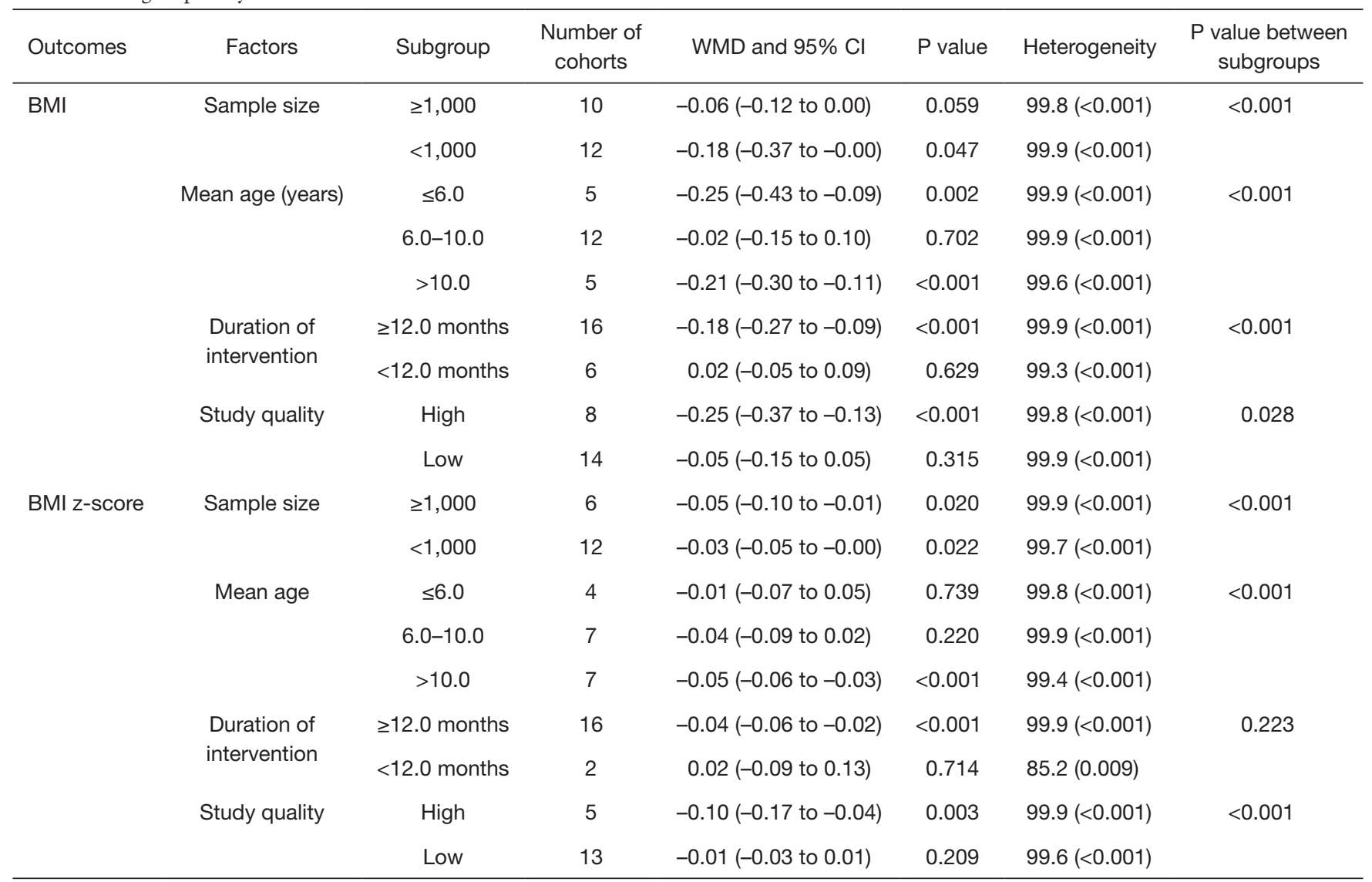

BMI, body mass index; WMD, weighted mean difference. 


\begin{tabular}{|c|c|c|c|}
\hline Study & & $\begin{array}{l}\text { Mean difference } \\
(95 \% \mathrm{Cl})\end{array}$ & $\%$ Weight \\
\hline James & 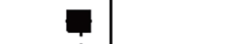 & $-0.04(-0.06,-0.02)$ & 5.6 \\
\hline Muckelbauer & & $-0.01(-0.01,-0.01)$ & 5.8 \\
\hline Siegrist & $\square$ & $0.05(0.04,0.06)$ & 5.7 \\
\hline Williamson (a) & 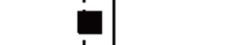 & $-0.03(-0.04,-0.02)$ & 5.8 \\
\hline Williamson (b) & & $-0.04(-0.04,-0.04)$ & 5.8 \\
\hline Natale & $\square$ & $-0.11(-0.12,-0.10)$ & 5.7 \\
\hline Johnston & & $-0.06(-0.06,-0.06)$ & 5.8 \\
\hline McFarlin & & $-0.04(-0.04,-0.04)$ & 5.8 \\
\hline Coen & & $-0.03(-0.03,-0.03)$ & 5.8 \\
\hline Llaurad"® & $\square$ & $0.04(0.04,0.04)$ & 5.8 \\
\hline Grydeland & & $-0.03(-0.03,-0.03)$ & 5.8 \\
\hline Larsen & & $-0.20(-0.22,-0.18)$ & 5.5 \\
\hline Davis & 口 & $0.06(0.05,0.07)$ & 5.8 \\
\hline Amini & 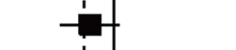 & $-0.03(-0.07,0.01)$ & 4.9 \\
\hline Taveras & & $-0.03(-0.03,-0.03)$ & 5.8 \\
\hline Ahmad & - & $0.08(0.01,0.15)$ & 3.4 \\
\hline G“' ${ }^{\circledR} \mathrm{mez}$ & & $0.01(0.01,0.01)$ & 5.8 \\
\hline Adab & & $-0.22(-0.22,-0.22)$ & 5.8 \\
\hline Overall & $\dot{\infty}$ & $\begin{array}{l}-0.04(-0.06,-0.02) ; P=0.001 \\
\text { (I-square: } 99.8 \% ; P<0.001)\end{array}$ & 100.0 \\
\hline-.5 & $\begin{array}{c}0 \\
\text { Mean difference }\end{array}$ & .5 & \\
\hline
\end{tabular}

Figure 4 Effect of dietary intervention on body mass index z-score.

yielded small and short-term benefits in BMI, BMI z-score and weight in children aged 6-11 years. However, whether the effectiveness of diet, physical activity and behavioral interventions on weight outcomes differed according to the individual characteristics were not elucidated (13). Hens et al. in a meta-analysis of 12 studies reported that children and adolescents who received diet or exercise interventions had better improvement in hepatic adiposity (55). However, the above meta-analyses evaluated by combining diet, physical activity and behavioral interventions on weight outcomes in children, and the effectiveness of dietary interventions on BMI and BMI z-score stratified by study or individuals' characteristics were not illustrated. Therefore, the current meta-analysis was conducted to evaluate the effectiveness of dietary intervention on weight outcomes in childhood.

The summary results indicated that children who received dietary interventions had greater BMI reduction when compared to those with usual healthcare, while several studies have reported inconsistent results. Jansen et al. have recruited 2,622 children and found that multi-component intervention showed association with greater reduction in $\mathrm{BMI}$ in children of grades 3-5, whereas this effect was not detected in children of grades 6-8 (20). Siegrist et al. have included 724 children and suggested that multi-component JuvenTUM intervention did not yield any benefit on BMI when compared with usual activities (22). Graf et al. have indicated that preventive strategies used in primary schools could significantly improve motor skills, whereas energy intake and weight showed significant increase (24). Sichieri et al. have suggested that the intake of decreased sugar-sweetened beverages was associated with greater reduction in BMI, especially in girls, whereas this effect was balanced by limited effectiveness in boys (26). Puder et al. have recruited 652 pre-school children and found that a multidimensional intervention has significantly increased aerobic fitness and reduced body fat, whereas no significant effect was observed on BMI (32). Magnusson et al. have indicated that children who received intervention showed inconsistent results with regard to fitness. Moreover, the intervention did not yield any statistically significant effect on body composition (15). There are several reasons for these inconsistencies, which were as follows: (I) the intensive of intervention outside the school was not feasible, which further required extensive involvement of 

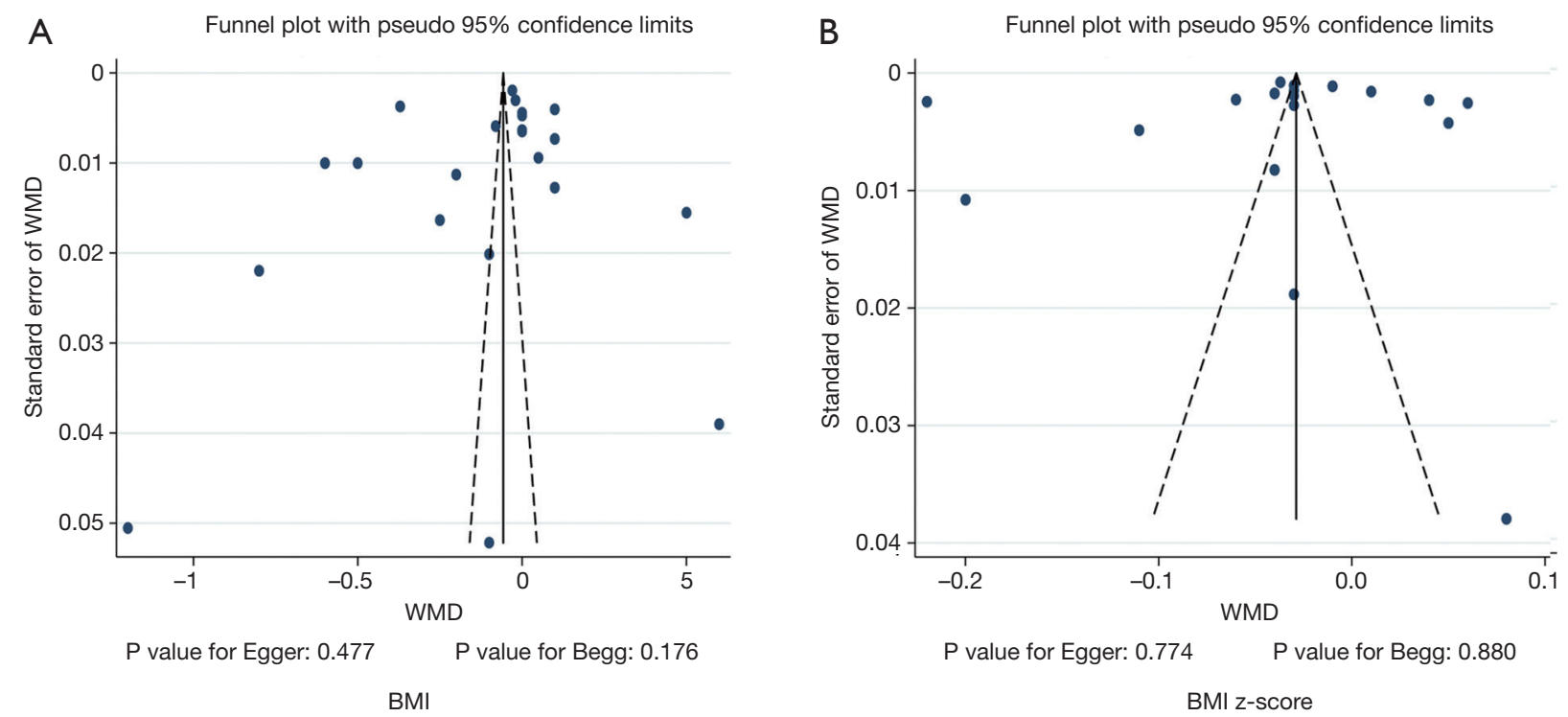

Figure 5 Funnel plots for body mass index (A) and body mass index z-score (B).

parents, community, and policies (56); (II) the prevalence of overweight at baseline differed, showing association with varied requirements to lower BMI; (III) additional specific measurements of the body fat are necessary to evaluate the effectiveness of dietary intervention as the effect of other components of intervention could affect $\mathrm{BMI}$ in generally non-obese children; and (IV) BMI is considered as a measure of general adiposity, providing no more information with regard to fat distribution, and these characteristics could be affected by other components of intervention.

In our study, individuals who received dietary intervention had greater reduction in BMI z-score. However, 5 of the included studies showed contrast conclusions (22,31,33-35). These studies indicated that children who received dietary interventions are associated with small reduction in BMI z-score. Moreover, they have pointed out that the prevalence of excess weight in school children with high socioeconomic status who received intervention showed a significant decrease. Furthermore, the skinfolds are more sensitive to changes in fat mass in children who received dietary interventions.

The results of subgroup analyses indicated the effectiveness of dietary interventions on BMI or BMI $\mathrm{z}$-score, and are affected by sample size, mean age, duration of interventions, and study quality. The potential reasons for this could be due to that the (I) sample size of retrieved trials might affect the weight of the overall analysis, showing association with more stable effect size and smaller standard deviation; (II) the mean age of children is significantly correlated with the behavior of individuals and learning ability, affecting the effectiveness of dietary interventions; (III) the duration of interventions could improve the knowledge and implementation ability, and long duration of interventions is always associated with greater effect size of dietary interventions; and (IV) study quality is significantly correlated with the reliability of results in individual trial, affecting the effectiveness of dietary intervention due to uncontrolled biases.

However, there are several limitations in this study that should be highlighted. Firstly, the components of educational interventions differed among the included trials, showing significant correlation with the effectiveness of dietary interventions on weight outcomes in childhood. Secondly, substantial heterogeneity across the included trials could not be fully interpreted through sensitivity and subgroup analyses, restricting the recommendation of conclusions in this study. Thirdly, publication bias was inevitable because of the analysis published RCTs. Fourthly, language bias was inevitable as non-English databases were not searched. Finally, the analysis was based on pooled data, restricting us to conduct a more detailed analysis.

In conclusion, the results of this meta-analysis indicated that dietary interventions showed significant improvement in BMI and BMI z-score in childhood. Moreover, the effectiveness of dietary interventions was affected by sample 
size, mean age, duration of interventions, and study quality. Further large-scale RCTs should be conducted to evaluate the differing effectiveness of dietary interventions between boys and girls.

\section{Acknowledgments}

Funding: This work was supported by National Key Research and Development Programme of China [No. 2016YFC1305301], Medical Scientific Research Foundation of Zhejiang Province, China [No. 2021RC019] and Science and Technology Bureau program of Yiwu [No. 20-3-259].

\section{Footnote}

Reporting Checklist: The authors have completed the PRISMA reporting checklist. Available at http://dx.doi. org/10.21037/tp-20-183

Conflicts of Interest: All authors have completed the ICMJE uniform disclosure form (available at http://dx.doi. org/10.21037/tp-20-183). The authors have no conflicts of interest to declare.

Ethical Statement: The authors are accountable for all aspects of the work in ensuring that questions related to the accuracy or integrity of any part of the work are appropriately investigated and resolved.

Open Access Statement: This is an Open Access article distributed in accordance with the Creative Commons Attribution-NonCommercial-NoDerivs 4.0 International License (CC BY-NC-ND 4.0), which permits the noncommercial replication and distribution of the article with the strict proviso that no changes or edits are made and the original work is properly cited (including links to both the formal publication through the relevant DOI and the license). See: https://creativecommons.org/licenses/by-nc-nd/4.0/.

\section{References}

1. WHO. Report of the commission on ending childhood obesity. 2016.

2. de Onis M, Blossner M, Borghi E. Global prevalence and trends of overweight and obesity among preschool children. Am J Clin Nutr 2010;92:1257-64.

3. McCormick DP, Sarpong K, Jordan L, et al. Infant obesity: are we ready to make this diagnosis? J Pediatr
2010;157:15-9.

4. Dattilo AM, Birch L, Krebs NF, et al. Need for early interventions in the prevention of pediatric overweight: a review and upcoming directions. J Obes 2012;2012:123023.

5. Balbus JM, Barouki R, Birnbaum LS, et al. Earlylife prevention of non-communicable diseases. Lancet 2013;381:3-4.

6. Arenz S, Ruckerl R, Koletzko B, et al. Breast-feeding and childhood obesity--a systematic review. Int J Obes Relat Metab Disord 2004;28:1247-56.

7. Griffiths LJ, Smeeth L, Hawkins SS, et al. Effects of infant feeding practice on weight gain from birth to 3 years. Arch Dis Child 2009;94:577-82.

8. Sahoo K, Sahoo B, Choudhury AK, et al. Childhood obesity: causes and consequences. J Family Med Prim Care 2015;4:187-92.

9. Dennison BA, Erb TA, Jenkins PL. Television viewing and television in bedroom associated with overweight risk among low-income preschool children. Pediatrics 2002;109:1028-35.

10. Salmon J, Campbell KJ, Crawford DA. Television viewing habits associated with obesity risk factors: a survey of Melbourne schoolchildren. Med J Aust 2006;184:64-7.

11. Birch LL. Development of food preferences. Annu Rev Nutr 1999;19:41-62.

12. O'Connor EA, Evans CV, Burda BU, et al. Screening for Obesity and Intervention for Weight Management in Children and Adolescents: Evidence Report and Systematic Review for the US Preventive Services Task Force. JAMA 2017;317:2427-44.

13. Mead E, Brown T, Rees K, et al. Diet, physical activity and behavioural interventions for the treatment of overweight or obese children from the age of 6 to 11 years. Cochrane Database Syst Rev 2017;6:CD012651.

14. Natale RA, Lopez-Mitnik G, Uhlhorn SB, et al. Effect of a child care center-based obesity prevention program on body mass index and nutrition practices among preschoolaged children. Health Promot Pract 2014;15:695-705.

15. Magnusson KT, Hrafnkelsson H, Sigurgeirsson I, et al. Limited effects of a 2-year school-based physical activity intervention on body composition and cardiorespiratory fitness in 7-year-old children. Health Educ Res 2012;27:484-94.

16. Kain J, Concha F, Moreno L, et al. School-based obesity prevention intervention in Chilean children: effective in controlling, but not reducing obesity. J Obes 2014;2014:618293.

17. Enö Persson J, Bohman B, Tynelius P, et al. Prevention of 
Childhood Obesity in Child Health Services: Follow-Up of the PRIMROSE Trial. Child Obes 2018;14:99-105.

18. James J, Thomas P, Cavan D, et al. Preventing childhood obesity by reducing consumption of carbonated drinks: cluster randomised controlled trial. BMJ 2004;328:1237.

19. Muckelbauer R, Libuda L, Clausen K, et al. A simple dietary intervention in the school setting decreased incidence of overweight in children. Obes Facts 2009;2:282-5.

20. Jansen W, Borsboom G, Meima A, et al. Effectiveness of a primary school-based intervention to reduce overweight. Int J Pediatr Obes 2011;6:e70-7.

21. Manios Y, Moschandreas J, Hatzis C, et al. Health and nutrition education in primary schools of Crete: changes in chronic disease risk factors following a 6-year intervention programme. Br J Nutr 2002;88:315-24.

22. Siegrist M, Lammel C, Haller B, et al. Effects of a physical education program on physical activity, fitness, and health in children: the JuvenTUM project. Scand J Med Sci Sports 2013;23:323-30.

23. Gentile DA, Welk G, Eisenmann JC, et al. Evaluation of a multiple ecological level child obesity prevention program: Switch what you Do, View, and Chew. BMC Med 2009; 7:49.

24. Graf C, Koch B, Falkowski G, et al. Effects of A SchoolBased Intervention on BMI and Motor Abilities in Childhood. J Sports Sci Med 2005;4:291-9.

25. Williamson DA, Champagne CM, Harsha DW, et al. Effect of an environmental school-based obesity prevention program on changes in body fat and body weight: a randomized trial. Obesity (Silver Spring) 2012;20:1653-61.

26. Sichieri R, Paula Trotte A, de Souza RA, et al. School randomised trial on prevention of excessive weight gain by discouraging students from drinking sodas. Public Health Nutr 2009;12:197-202.

27. Johnston CA, Moreno JP, El-Mubasher A, et al. Impact of a school-based pediatric obesity prevention program facilitated by health professionals. J Sch Health 2013;83:171-81.

28. McFarlin BK, Johnston CJ, Carpenter KC, et al. A oneyear school-based di-et/exercise intervention improves non-traditional disease biomarkers in Mexi-can-American children. Matern Child Nutr 2013;9:524-32.

29. De Coen V, De Bourdeaudhuij I, Vereecken C, et al. Effects of a 2-year healthy eating and physical activity intervention for 3-6-year-olds in communities of high and low socio-economic status: the POP (Prevention of Overweight among Pre-school and school children) project. Public Health Nutr 2012;15:1737-45.

30. Kesztyüs D, Schreiber A, Wirt T, et al. Economic evaluation of URMEL-ICE, a school-based overweight prevention programme comprising metabolism, exercise and lifestyle intervention in children. Eur J Health Econ 2013;14:185-95.

31. Llargués E, Recasens A, Franco R, et al. Medium-term evaluation of an educational intervention on dietary and physical exercise habits in schoolchildren: the Avall 2 study. Endocrinol Nutr 2012;59:288-95.

32. Puder JJ, Marques-Vidal P, Schindler C, et al. Effect of multidimensional life-style intervention on fitness and adiposity in predominantly migrant preschool children (Ballabeina): cluster randomised controlled trial. BMJ 2011;343:d6195.

33. Davis SM, Myers OB, Cruz TH, et al. CHILE: Outcomes of a group randomized controlled trial of an intervention to prevent obesity in preschool Hispanic and American Indian children. Prev Med 2016;89:162-8.

34. Ahmad N, Shariff ZM, Mukhtar F, et al. Family-based intervention using face-to-face sessions and social media to improve Malay primary school children's adiposity: a randomized controlled field trial of the Malaysian REDUCE programme. Nutr J 2018;17:74.

35. Gómez SF, Casas Esteve R, Subirana I, et al. Effect of a community-based childhood obesity intervention program on changes in anthropometric variables, incidence of obesity, and lifestyle choices in Spanish children aged 8 to 10 years. Eur J Pediatr 2018;177:1531-9.

36. Grydeland M, Bjelland M, Anderssen SA, et al. Effects of a 20-month cluster randomised controlled school-based intervention trial on BMI of school-aged boys and girls: the HEIA study. Br J Sports Med 2014;48:768-73.

37. Larsen KT, Huang T, Ried-Larsen M, et al. A MultiComponent Day-Camp Weight-Loss Program Is Effective in Reducing BMI in Children after One Year: A Randomized Controlled Trial. PLoS One 2016;11:e0157182.

38. Amini M, Djazayery A, Majdzadeh R, et al. A SchoolBased Intervention to Reduce Excess Weight in Overweight and Obese Primary School Students. Biol Res Nurs 2016;18:531-40.

39. Taveras EM, Marshall R, Sharifi M, et al. Comparative Effectiveness of Clinical-Community Childhood Obesity Interventions: A Randomized Clinical Trial. JAMA Pediatr 2017;171:e171325.

40. Ojeda-Rodríguez A, Zazpe I, Morell-Azanza L, et 
al. Improved Diet Quality and Nutrient Adequacy in Children and Adolescents with Abdominal Obesity after a Lifestyle Intervention. Nutrients 2018;10:1500.

41. Adab P, Pallan MJ, Lancashire ER, et al. Effectiveness of a childhood obesity prevention programme delivered through schools, targeting 6 and 7 year olds: cluster randomised controlled trial (WAVES study). BMJ 2018;360:k211.

42. Moher D, Liberati A, Tetzlaff J, et al. Preferred reporting items for systematic reviews and meta-analyses: the PRISMA statement. PLos Med 2009;6:e1000097.

43. Higgins JP, Altman DG, Gøtzsche PC, et al. The Cochrane Collaboration's tool for assessing risk of bias in randomised trials. Bmj 2011;343:d5928.

44. DerSimonian R, Laird N. Meta-analysis in clinical trials. Controlled Clinical Trials 1986;7:177-88.

45. Ades AE, Lu G, Higgins JP. The interpretation of randomeffects meta-analysis in decision models. Med Decis Making 2005;25:646-54.

46. Deeks J, Higgins J, Altman D, et al. Analyzing data and undertaking me-ta-analyses. Cochrane Handbook for Systematic Reviews of Interventions 5. 0. 1. Oxford, UK: The Cochrane Collaboration, 2008.

47. Higgins JP, Thompson SG, Deeks JJ, et al. Measuring inconsistency in me-ta-analyses. BMJ 2003;327:557-60.

48. Tobias A. Assessing the influence of a single study in metaanalysis. Stata Tech Bull 1999;47:15-7.

49. Altman DG, Bland JM. Interaction revisited: the difference between two estimates. BMJ 2003;326:219.

50. Egger M, Davey Smith G, Schneider M, et al. Bias in meta-analysis detected by a simple, graphical test. BMJ 1997;315:629-34.

51. Begg CB, Mazumdar M. Operating characteristics of a rank correlation test for publication bias. Biometrics 1994;50:1088-101.

52. van Hoek E, Feskens EJ, Bouwman LI, et al. Effective interventions in over-weight or obese young children: systematic review and meta-analysis. Child Obes 2014;10:448-60.

53. Brown T, Smith S, Bhopal R, et al. Diet and physical activity interventions to prevent or treat obesity in South Asian children and adults: a systematic review and metaanalysis. Int J Environ Res Public Health 2015;12:566-94.

54. Oosterhoff M, Joore M, Ferreira I. The effects of schoolbased lifestyle interventions on body mass index and blood pressure: a multivariate multilevel me-ta-analysis of randomized controlled trials. Obes Rev 2016;17:1131-53.

55. Hens W, Vissers D, Hansen D, et al. The effect of diet or exercise on ectopic adiposity in children and adolescents with obesity: a systematic review and me-ta-analysis. Obes Rev 2017;18:1310-22.

56. van Sluijs EM, McMinn AM, Griffin SJ. Effectiveness of interventions to promote physical activity in children and adolescents: systematic review of con-trolled trials. BMJ 2007;335:703.
Cite this article as: Long Q, Zhang T, Chen F, Wang W, Chen X, Ma M. Effectiveness of dietary interventions on weight outcomes in childhood: a systematic review meta-analysis of randomized controlled trials. Transl Pediatr 2021;10(4):701714. doi: 10.21037/tp-20-183 